Article

\title{
Aluminium electrodeposition fron ionic liquid: effect of deposition temperature and sonication
}

\author{
Enrico Berretti ${ }^{1}$, Stefano Caporali 2,*, Andrea Giaccherini ${ }^{3}$, Stefano Mauro Martinuzzi ${ }^{4}$ and \\ Massimo Innocenti ${ }^{5}$ \\ 1 Dipartimento di Chimica, Università di Firenze, Sesto Fiorentino, FI 50019, Italy; enrico.berretti@unifi.it \\ 2 Consorzio Interuniversitario Nazionale Per la scienza e Te cnologia dei Ma te riali (INSTM) and Istituto \\ SistemiComplessi(ISC), Sesto Fiorentino 50019, Italy; stefano.caporali@unifi.it \\ 3 Dipartimento di Chimica, Unive rsità di Firenze, Sesto Fiorentino, FI 50019, Italy; andrea.gia ccherini@unifi.it \\ 4 Dipartimento di Chimica, Università di Firenze, Sesto Fiorentino, FI 50019, Italy; stefano.martinuzzi@unifi.it \\ 5 Dipartimento di Chimica, Università di Firenze, Sesto Fiorentino, FI 50019, Italy; m.innocenti@unifi.it \\ * Correspondence: stefano.caporali@unifi.it; Tel.: +39-055-457-3119
}

Received:14 April 2016; Accepted: 30 April 2016; Published: 2 May 2016

\begin{abstract}
Since their discovery, ionic liquids (IL) have attracted a wide interest for their potential use as medium for many chemical processes, which vary from extraction, to catalysis, to organic synthesis to energy storage. Their use as electrochemical media allowed the electrodeposition of metals that are impossible to reduce in aqueous media. In particular, the first generation ILs, namely chloroaluminated ILs, have made possible the deposition of aluminium from his chloride salt. Despite the discovery of this process in the nineties, now adays aluminium electrodeposition from chloroaluminate ILs still maintains a number of open issues regarding both fundamental and technological aspects. The present communication aims to shed some light about this process as concerns the effect of deposition parameters on the quality of the deposits. Thick $(20 \mu \mathrm{m})$ Al-coatings were electrodeposited on brass substrates at different temperature and mixing conditions. The so obtained coatings were investigated by means of scanning electron microscope, rugosimetry and X-ray diffraction to asses their morphology and phase composition. Finally, with the intent to correlate the coating structures with their corrosion properties, electrochemical corrosion tests were performed.
\end{abstract}

Keywords: Ionic Liquids; Aluminium; Electrodeposition; Surface morphology; Sonication; Corrosion resistance.

\section{Introduction}

Since its invention, the Heroult-Hall process [1] has been the conventional process for the production of metallic aluminium. It is based upon the electroreduction of alumina on a cryolite melt by using graphite electrodes. The high temperature required (in the order of $900{ }^{\circ} \mathrm{C}$ ) and the emission of toxic gaseous by-products such as fluorine and carbon monoxide, rendered the research for greener and safer alternative techniques highly actractive. The introduction of Ionic Liquids (ILs) (namely room temperature molten salts) as electrochemical media for the aluminium electrodeposition offered a very promising route to succeed in this goal. Since the first pioneeristic studies in the 90th [2], a large number of investigations successfully reported, at lab scale, the electrodeposition of aluminium at room or nearly room temperature. Different ty pe of ionic liquids [3-7], ionic liquid mixtures and additives [8,9] were proposed to achieve the electrodeposition of bulk or nanostructured, dull or matt Al-coatings. However, with the aim of the process industrialization for the deposition of thick al coatings, chloroaluminate ionic liquids, without additives, seems to constitute the better compromise between the quality of the deposit and the stability of the electroplating bath. Beside the handling difficulties, mainly due to the vigorous 
reaction with atmospheric moisture that characterize these media, their high aluminium content, reduced viscosity and electrochemical stability, allow high deposition rate; in the order of 10-20 $\mu \mathrm{m} . \mathrm{h}^{-1}$ and long working time without maintenance or replenish chemicals. Scheme of the Al-electroplating process by means of chloroaluminate ILs is depicted in figure 1 . .

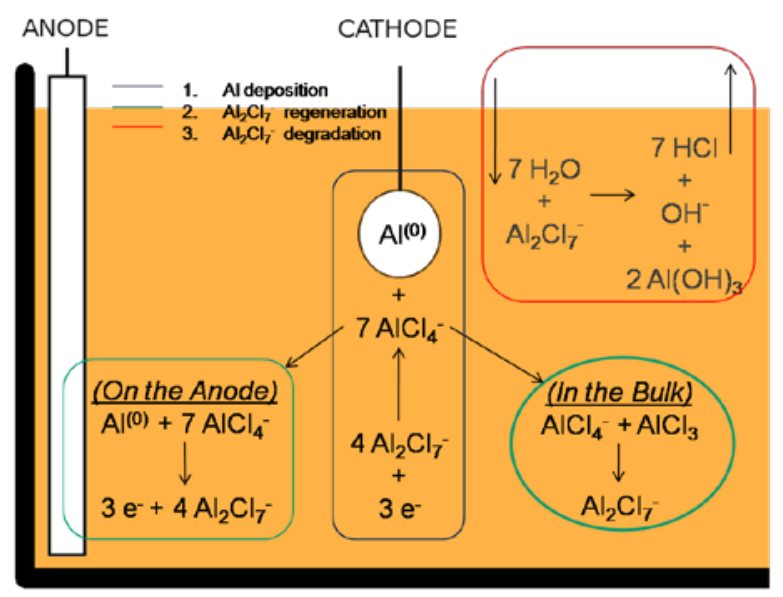

Figure 1. Scheme of the Alelectroplating process from chloroaluminated ILs. Al is reduced at the cathode while at the anode the electrtoactive species is regenerated by aluminium dissolution and the reaction with $\mathrm{AlCl}_{4}$. The red box depicts the reaction with moisture.

The Al-coatings obtained at lab scale with this technology have been successfully used as protective layers for structural materials such as as carbon steel [8-12], magnesium alloys[10], light weight alloys [11] etc. the anticorrosion properties of the Al-coating are based upon the formation of a dense passivation layer composed by aluminium oxide. It prevents further corrosive action towards the metal beneath. It is evident as these anticorrosion properties invariably requires the formation of a continuous alumina layer, and therefore $t$ assess full corrosion protection free-of-cracks aluminium coatings must homogeneously distributed over the substrate material.

In order to obtain high quality Al-coatings the study of the effect of solution parameters such as temperature and stirring conditions on the deposition rate, the crystal structure, the surface morphology and roughness is therefore mandatory. Electrodeposition in a stirred solutions has the advantage of reducing the diffusion layer, improving the deposition rate and the homogeneity of the deposit. However, even if some studies investigated the effect of temperature [12], very little work has been reported on the effect of solution stirring [13], [14] and, to the best of our knowledge, none regarding the effect of sonication.

For such reasons, aiming to determine the better operative conditions for the industrialization of the Al plating process, we investigated the effects of temperature and mixing conditions, both alone and combined on the electrodeposition of $\mathrm{Al}$ from the ionic liquid $[\mathrm{Bmim}] \mathrm{Cl} / \mathrm{AlCl}$ $(40 / 60 \mathrm{~mol} \%)$. Finally, the deposits were characterized by SEM investigation, roughness measurement, X-Ray diffraction and electrochemical corrosion tests to assess the condition more suitable to achieve smooth, homogeneous and thick Al coatings.

\section{Materials and Methods}

\subsection{Chemicals}

The electroplating bath was constituted by 1-butyl-3-methyl-imidazolium chloride $([\mathrm{Bmim}] \mathrm{Cl}) / \mathrm{AlCl}_{3}(40 / 60 \mathrm{~mol} \%)$. It was supplied by IoLiTech (Heilbronn, Germany) and used as received without further purification.

\subsection{Electrode materials}


The substrates on which the Al-coatings were deposited are constituted by brass (Cu 63\%, Zn $37 \%$ ) tokens of 12 and $25 \mathrm{~mm}$ diameter. They were grinded with SiC paper down to 1200 grit and polished with diamond suspension (Metadi 3 micron, Buehler), rinsed with tap water and sonicated in acetone (Chem-Lab a.r. 99.5\%) for 5 minutes. Then they were rinsed again in tap water and soaked in $\mathrm{HCl} 1 \mathrm{M}$ for 3 minutes, rinsed in distilled $\mathrm{w}$ ater, sonicated again in acetone for 5 minutes and then dried under N2. Prior to start the electrodeposition, the working electrodes were electrochemically cleaned directly in the electroplating bath by applying a positive (oxidative) current $\left(2.5 \mathrm{~mA}^{\mathrm{c}} \mathrm{cm}^{-2}\right)$ for 30 seconds.

\subsection{Deposition parameters}

The plating process was carried out inside a nitrogen filled glove box (Iteco mod 10A), with water content below 20 ppm. The deposits were produced in current controlled (galvanostatic) conditions at $10 \mathrm{~mA} . \mathrm{cm}^{-2}$ using an AMEL Mod. 7050 potentiostat, a circular anode constituted by a pure aluminium foil (Goodfellow 99.0\%) and brass tokens as cathodes. Two different deposition set-ups were used with the same geometry but different anode/cathode surface ratio (see figure 2a and $2 \mathrm{~b}$ ). Depositions were performed in quiet or under mixing conditions by means of mechanical stirring (magnetic bar, $320 \mathrm{rpm}$ ) or sonication (Qsonica Sonicator Q500 500W 20kHz operating at 30\% of maximum power; with different duty cycles). In the experiments on which sonication was introduced, the horn was placed on the cathode side as depicted in figure $2 \mathrm{~b}$.

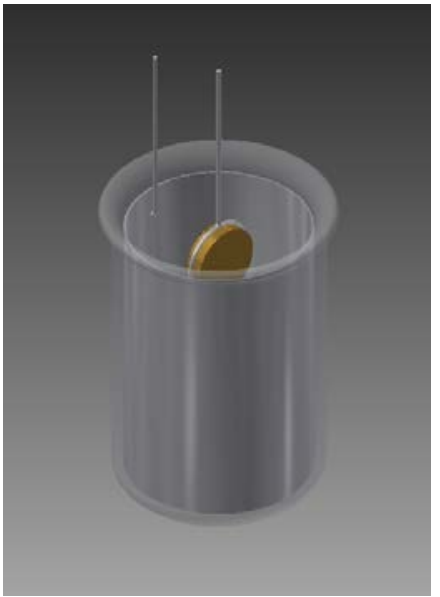

(a)

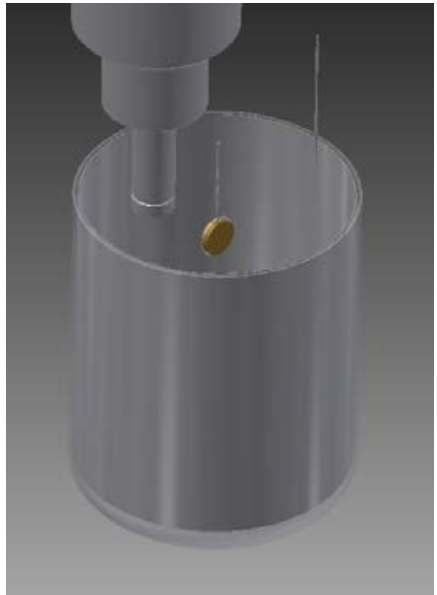

(b)

Figure 2. Scheme of experimental set-ups used for (a) the temperature and (b) sonication experiments.

\subsection{Characterization of the deposits}

The morphology of the coatings was investigated by Scanning Elecron Microscopy (Hitachi S-2300) operating at $20 \mathrm{kV}$, while the average roughness was measured using a Hommel Tester W55. The measurements were obtained performing 5 different and independent tests in randomly chosen areas of the sample. The measures were performed scanning $4.8 \mathrm{~mm}$ of surface at $0.2 \mathrm{~mm} \mathrm{~s}^{-1}$ of scan rate. The parameters employed were $\lambda c=0.8 \mathrm{~mm}$ and $\lambda \mathrm{c} / \lambda \mathrm{s}=300 \mathrm{using}$ a filter ISO 11562(MI), for every type of sample the $R_{a}, R_{z}$, $R_{z I S O}$ and $R_{t}$ values were calculated (see Table 1 and Table 3 ).

\subsection{Percentage yield}

Since the viscosity of the IL used is much higher respect to the aqueous solutions, the formation of dendritic deposits is favoured, especially when mild operative conditions (low temperature, no mixing) are employed. If dendritic coatings were formed the detachment of parts of the deposit during the rinsing operations can not be neglected. To take into account this mass loss, yield 
parameter was introduced (equation (1)) as the percent ratio between the effective mass of the obtained deposit and the theoretical mass calculated from the Faraday law.

$$
\text { Yield } \%=\frac{\text { Measured Mass }}{\text { Theoretical Mass }} \times 100
$$

The "Measured Mass" is given by the difference between the masses of the cathode after and prior the deposition process. Yield not only provides a glimpse on the efficiency of the coating process, but also gives us an idea of its thickness. Obviously lower yields lead to thinner deposits, whilehigher yields point on thicker ones.

\subsection{XRD analysis}

The phase determination of the synthetic products was carried out through powder X-ray diffraction (XRD), performed using a XRD Bruker D8 Advance powder diffractometer employing $\mathrm{Cu} \mathrm{K} \alpha(1.54187 \AA)$ radiation in the $2 \theta$ range $36-80^{\circ}$, applying a step size of $0.022^{\circ} 2 \theta$ and a step counting time of $0.27 \mathrm{~s}$. Deconvultion of the peaks in the powder scan have been performed by means of the single line profile analysis [14], involving the fitting of the peaks with 2 Voigt functions (one for the $\mathrm{K} \square$ and for $\mathrm{K} \square$ ). Voigt function is a convolution of a Lorentzian and a Gaussian functions. Gaussian width is related to the average strain of the crystallite while the Lorentzian width is related to the crystallite size. [14] On this background, it is possible to retrieve information on the effect of the experimental conditions on the strain and size of the crystals as well as the texture coefficient. The texture coefficient is defined in equation (2):

$$
\mathrm{T}(h k l)=\frac{A(h k l) / A_{0}(h k l)}{\sum_{h k l} \mathrm{~A}(h k l) / A_{0}(h k l)}
$$

Where $\mathrm{T}(\mathrm{hkl})$ is the texture coefficient for the $(\mathrm{hkl})$ plane, $\mathrm{A}(\mathrm{hkl})$ and $\mathrm{A}_{0}(\mathrm{hkl})$ are respectively the experimental and theoretical area under the Voigt curve of the (hkl) plane. $A_{0}(\mathrm{hkl})$ has been simulated using the program Mercury and structural information by Wycoff [15-17].

\subsection{Electrochemical corrosion test}

The electrochemical corrosion tests were performed using a corrosion cell from Princeton Applied Research (Flat cell KO235) in aerated 3.5\% NaCl ( $>99.5 \%$ from Merck) solution at room temperature $\left(20-23^{\circ} \mathrm{C}\right)$. The potentiostat was a PAR model 2273 controlled by PowerSuite 2.58 software. The classical three electrode set-up was employed using a platinum grid as counter electrode and a SCE reference electrode separated from the solution with an ion conducting glass frit, the working electrode surface was $1.0 \mathrm{~cm}^{2}$. The tests were performed on the aluminized samples without further treatment. Every sample was kept in the saline solution for at least $16 \mathrm{~h}$ in order to allow the stabilization of the system than potentiodynamic (PD) experiment were recorded starting from $-0.250 \mathrm{~V}$ respect to the free corrosion potential at the scan rate of $0.4 \mathrm{mVs}^{-1}$.

\section{Results}

\subsection{Effect of temperature}

Even if the effect of temperature on the morphology of the Al-coatings has been previously reported up to $55^{\circ} \mathrm{C}$ [12] we extend the investigation at higher temperatures. In this set of experiments, while maintaining quiet the electroplating bath, the $\mathrm{Al}$ deposition was performed at three different temperatures: $50^{\circ} \mathrm{C}, 70^{\circ} \mathrm{C}$ and $90^{\circ} \mathrm{C}$. During the experiments the potential-time curves (figure 3) were recorded in order to extrapolate the induction time (the time needed to reach a stable deposition potential) and the equilibrium potential. The last one provide direct insight about the 
overpotential needed to obtain the deposition and therefore the energy consumed for the plating process.

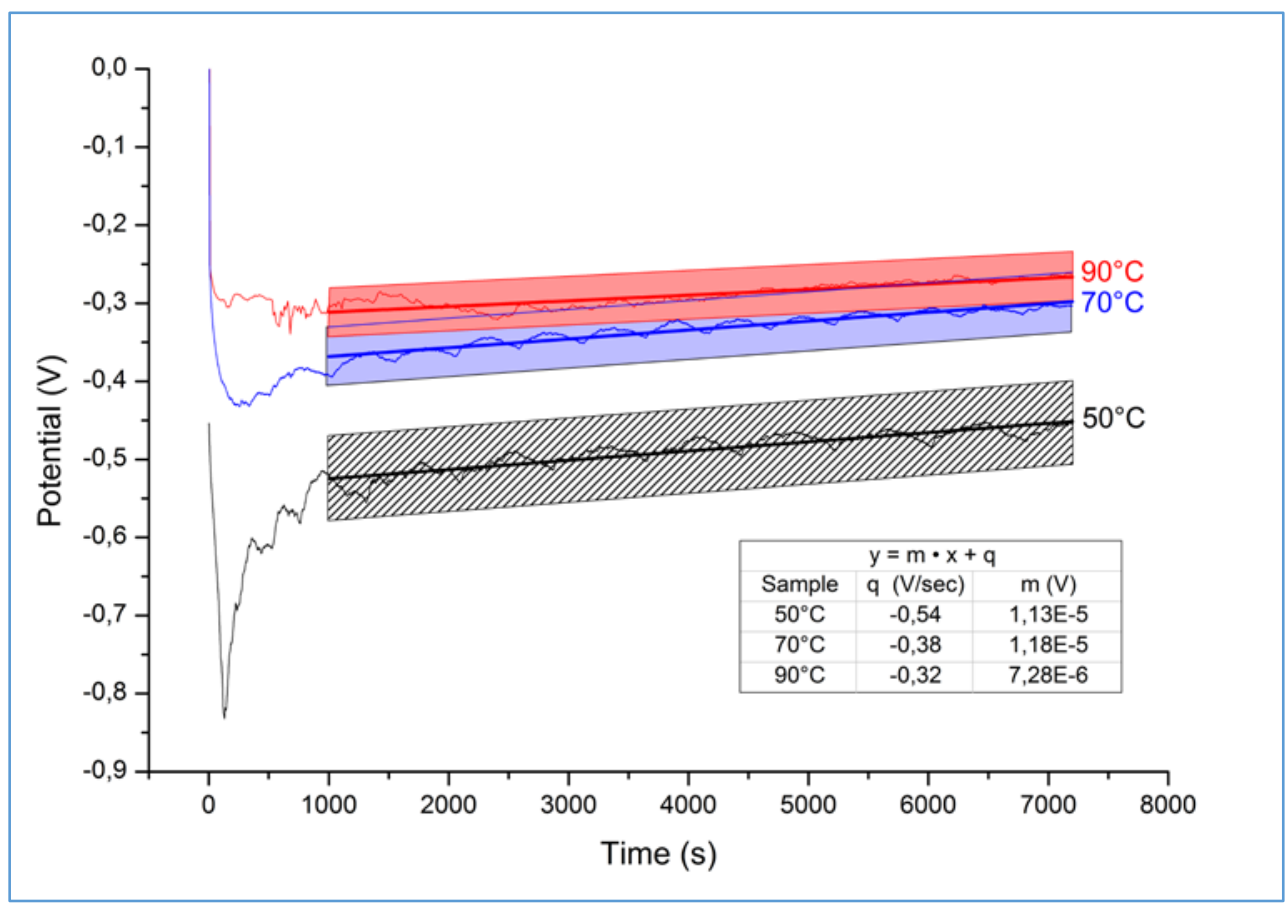

Figure 3. Potential-time curves obtained at different temperatures. Galvanostatic deposition 10 mA.cm-2 deposition time 2 hours. The inset depicts the results of da ta linear fitting. The slope of the curves decreases increasing the temperature.

In accordance with previous investigations in similar ionic liquids [12] the stimulating effect of the temperature tow ard the electroreduction process is confirmed. As the temperature increase more and higher, the induction time became shorter, the equilibrium potentials less negative and the fitting curve are characterized by smaller slopes indicating little surface increase as consequence of the formation of smoother deposits. This qualitative observation was supported by more quantitative roughness measurements. The data summarized in table 1, show the decrease of the surface roughness and the formation of more homogeneous deposits (lower relative error in the roughness measurement) as a consequence of the temperature increase.

Table 1. Roughness parameters for the samples obtained at different temperature.

\begin{tabular}{c|c|c|c|c}
\hline Sample & Rt $(\square \mathrm{m})$ & Ra & $\begin{array}{c}\text { RzISO } \\
(\square \mathrm{m})\end{array}$ & Rz $(\square \mathrm{m})$ \\
\hline Temp. $50^{\circ} \mathrm{C}$ & $32,9 \pm 1,2$ & $3,7 \pm 1,1$ & $25,5 \pm 4,1$ & $23,3 \pm 2,8$ \\
Temp. $70^{\circ} \mathrm{C}$ & $21,7 \pm 10,5$ & $2,1 \pm 0,2$ & $14,9 \pm 5,8$ & $13,4 \pm 4,8$ \\
Temp. $90^{\circ} \mathrm{C}$ & $4,2 \pm 0,1$ & $0,3 \pm 0,1$ & $3,1 \pm 0,1$ & $2,90 \pm 0,1$ \\
\hline
\end{tabular}

SEM investigation (figure 4) strengthen this trend evidencing the change of morphology; from pinnacle type deposits at $50^{\circ} \mathrm{C}$ to homogeneous crystalline structure at $90^{\circ} \mathrm{C}$. 


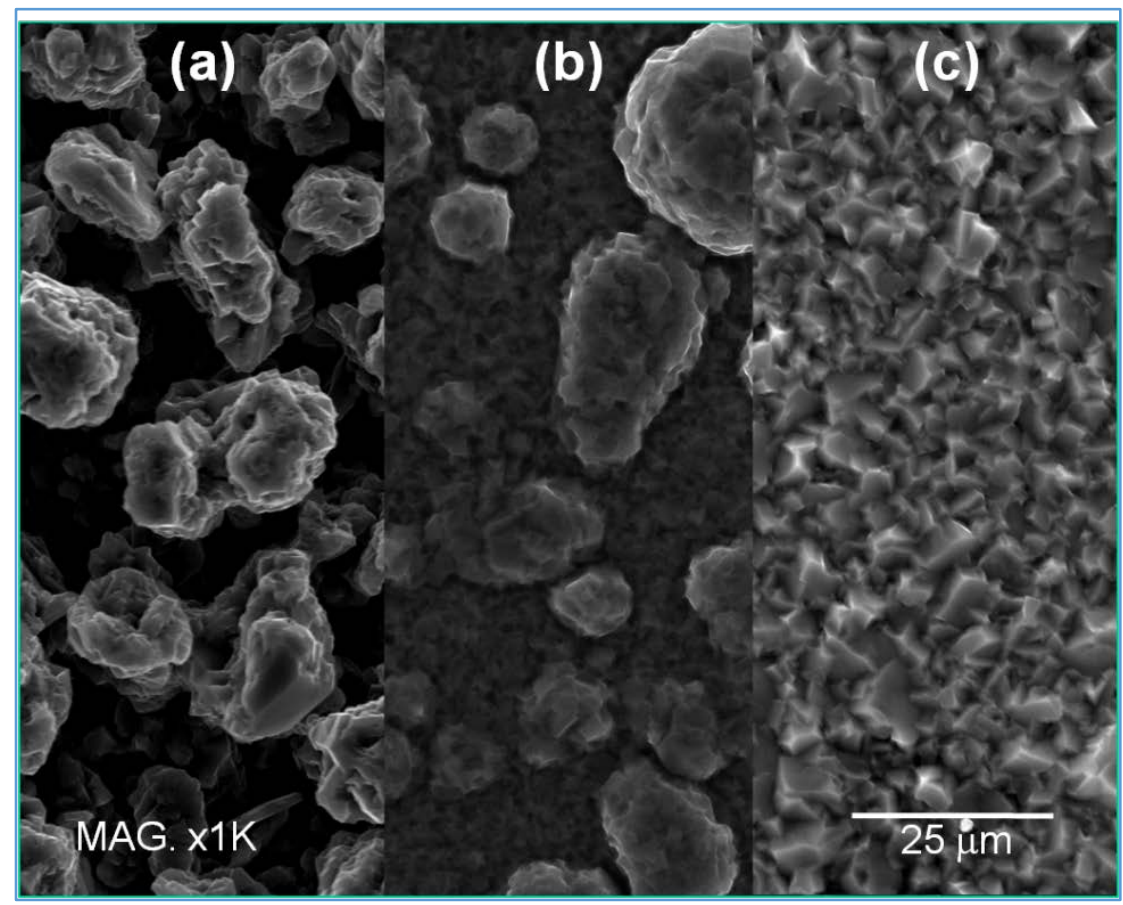

Figure 4. SEM images of the samples obtained at different temperatures; (a) $50^{\circ} \mathrm{C}$, (b) $70^{\circ} \mathrm{C}$ and (c) $90^{\circ} \mathrm{C}$. Deposition time, 2 hours.

Even if $100 \%$ yield has never been reached, an increase of the process yield with temperature can be noticed (Table 2).

Table 2. \% Yield obtained from the temperature samples

\begin{tabular}{l|c|c|c}
\hline & $50^{\circ} \mathrm{C}$ & $70^{\circ} \mathrm{C}$ & $90^{\circ} \mathrm{C}$ \\
\hline Yield $\%$ & $79 \%$ & $86 \%$ & $88 \%$ \\
\hline
\end{tabular}

Unfortunately, repeated experiments demonstrate that, for temperature higher than $70{ }^{\circ} \mathrm{C}$ the ILs, undergoes very rapid degradation. That impair the use of higher temperature for industrial and applicative purposes. Therefore the following experiments were carried out at $60^{\circ} \mathrm{C}$ maximum temperature.

\subsubsection{Corrosion tests}

The samples obtained at different temperature were investigated to asses the anticorrosion properties of the coatings. Figure 5 show the potentiodynamics curves relative to these samples. There are no substantial variations among the free corrosion potentials. Only a modest decrease in the corrosion current (ic) is detectable as function of the temperature. That is reasonably due to the decrease in sample roughness and, therefore, the reduction of the cathode surface. 


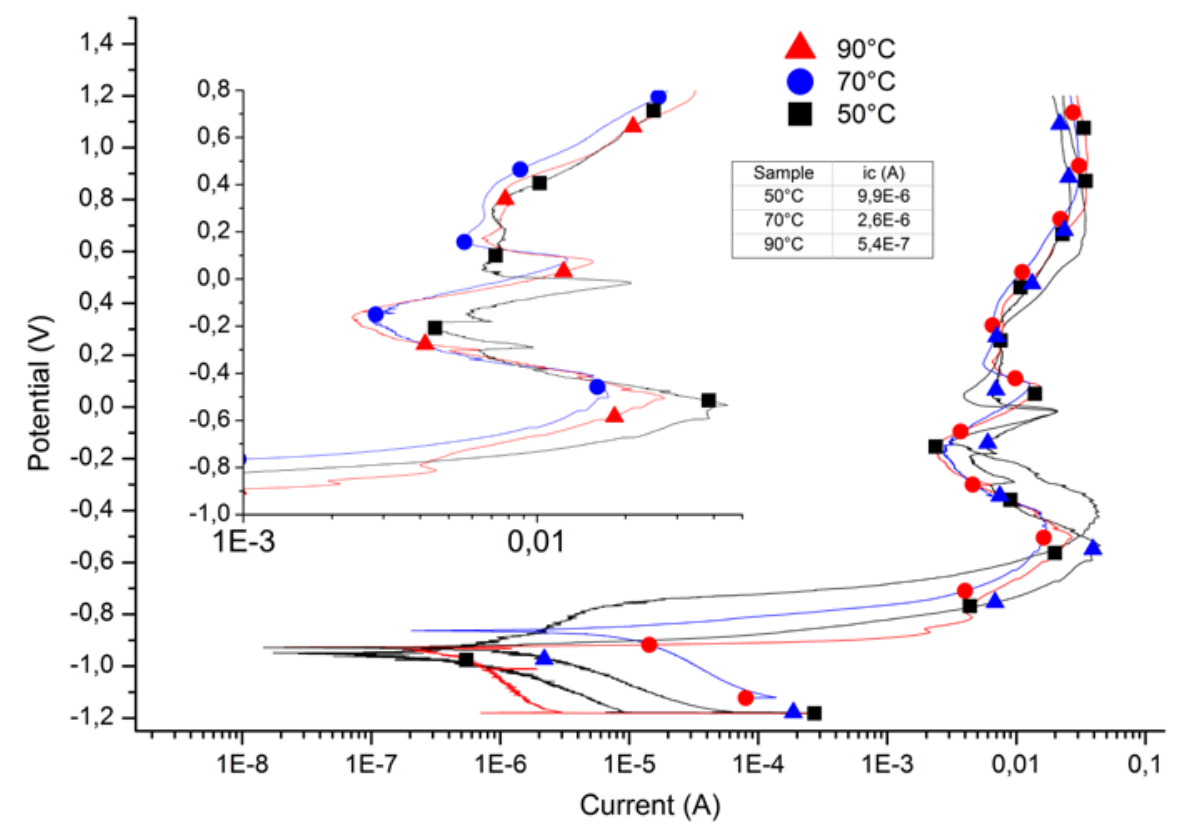

Figure 5. Potentiodynamic curves in 3.5\% NaClaerated a queous solution. Scan rate $0.4 \mathrm{mV} \cdot \mathrm{sec}^{-1}$. The inset de picts the corrosion current values.

\subsection{Sonication}

This series of samples were produced employing a bigger set-up (Figure 2(b)), necessary to immerse the sonication horn in the bath, and applying two different sonication duty cycles. The first one (mild sonication), consisted in a 1 second on (30\% power) every ten seconds; the second (stronger sonication) consisted in a 1 second on (30\% power) every two seconds. We refer to these condition as "Sonication 1 to 10 " and "Sonication 1 to 1 " respectively. Quiet depositions were also carried out for comparison. All these experiments were carried out at $20^{\circ} \mathrm{C}$.

The potential-time curves depicted in Figure 6 show a longer induction time, while the equilibrium potential show the same trend the temperature series; stronger sonication leads to less negative deposition potentials turning in a easier deposition process. On the other side the roughness measurements summarized in Table 3 depict an opposite trend respect to the temperature series indicating, on the whole, a surface roughness increase as a function of the sonication effect. This counter intuitive behavior is unraveled by SEM investigation (Figure 7). Even if the nucleation and growth mechanism remain unchanged, increasing the sonication pow er leads to the formation of larger crystals that account for the increased surface roughness.

Table 4 depicts the \% yield obtained at different sonication. It is worth to note that by using sonication the $100 \%$ yield is achieved. On the other hand, the deposit obtained at $20{ }^{\circ} \mathrm{C}$ without sonication presents a massive deposit loss (yield about $60 \%$ ). That is reasonably due to the formation of dendritic deposit that were removed during the sample rinsing. The formation of dendrites not only negatively affects the deposition yield but also, decreasing the deposit thickness, reduces the roughness of these deposits. 


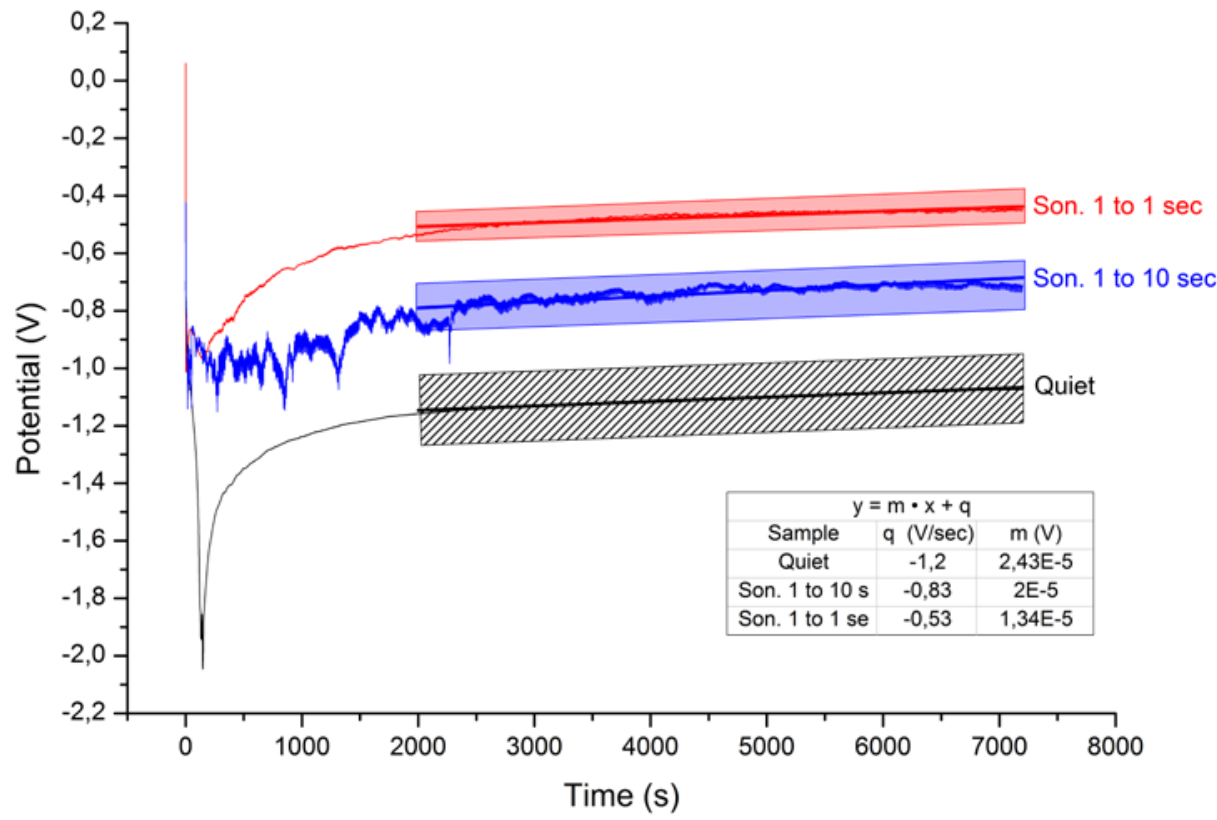

Figure 6. Potential-time curves obtained at different sonication. Galvanos ta tic de position $10 \mathrm{~mA} . \mathrm{cm}^{2}$, deposition time 2 hours. The inset de picts the results of da ta linear fitting.

Table 3. Roughness parameters for the sonication samples.

\begin{tabular}{c|r|c|r|r}
\hline Sample & Rt $(\square \mathrm{m})$ & Ra & \multicolumn{1}{|c}{$\begin{array}{c}\text { RzISO } \\
(\square \mathrm{m})\end{array}$} & Rz $(\square \mathrm{m})$ \\
\hline Quiet deposit & $4,2 \pm 0,3$ & $0,4 \pm 0,1$ & $3,6 \pm 0,2$ & $3,4 \pm 0,2$ \\
Sonication 1 to 10. & $11,7 \pm 1,3$ & $0,7 \pm 0,1$ & $8,5 \pm 0,8$ & $7,2 \pm 0,6$ \\
Sonication 1 to 1. & $17,0 \pm 1,2$ & $1,7 \pm 0,1$ & $13,6 \pm 0,6$ & $12,7 \pm 0,4$ \\
\hline
\end{tabular}

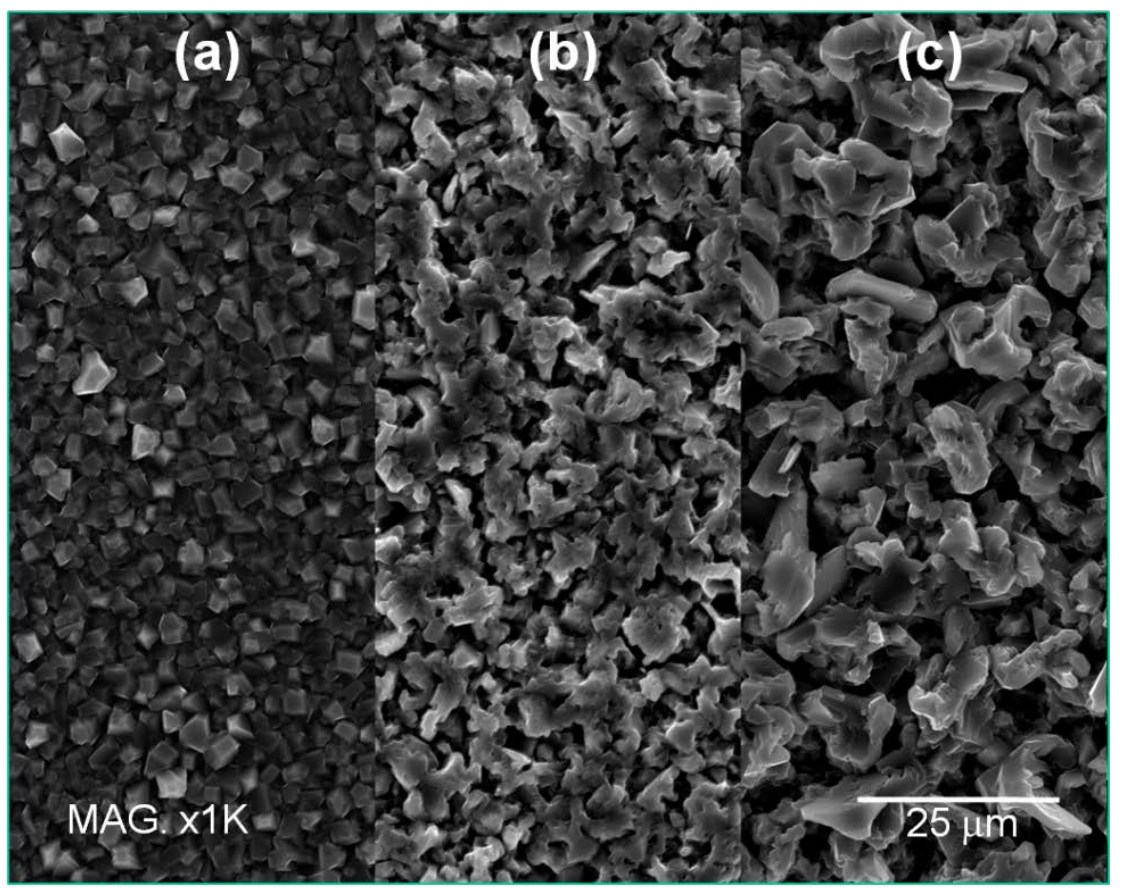


Figure 7. SEM images of the samples obtained using different sonication; (a) Quiet solution, (b) Sonication 1 to 10 (c) Sonication 1 to 1 .

Table 4. Roughness parameters for the sonication samples.

\begin{tabular}{c|c|c|c}
\hline & Quiet Deposition & Son. 1 sec. Every $10 \mathrm{sec}$. & Son. $1 \mathrm{sec}$. Every $1 \mathrm{sec}$. \\
\hline$\%$ Yield & $60 \%$ & $100 \%$ & $100 \%$ \\
\hline
\end{tabular}

\subsubsection{Corrosion tests}

Figure 8 depicts the potentiodynamic curves recorded on the sample obtained applying different sonication conditions. The curves are very similar showing almost the same open circuit potential values and corrosion currents. The anodic branch of the curve presents very similar shape for all the samples but the quiet. In this case the lower thickness o the deposit and the formation of dendritic coating can be claimed tojustify the observed variation.

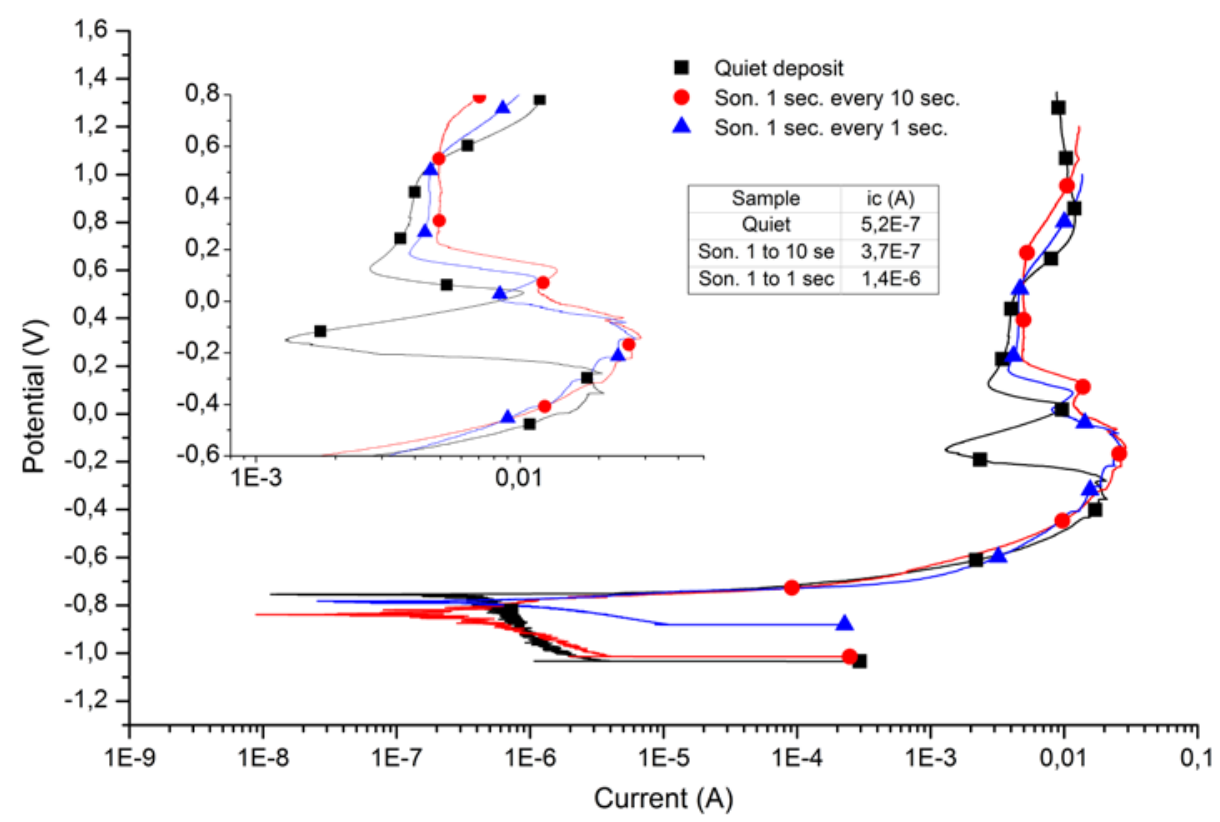

Figure 8. Potentiodynamic curves in $3.5 \% \mathrm{NaCl}$ aerated aqueous solution. Scan rate $0.4 \mathrm{mV} \cdot \mathrm{sec}^{-1}$. The inset de picts the corrosion current values.

\subsection{Combined effects}

In order to study the influence of both temperature and sonication, a new set of deposits were obtained using a combination of these parameters. Three temperature $\left(20^{\circ} \mathrm{C}, 40^{\circ} \mathrm{C}\right.$ and $\left.60^{\circ} \mathrm{C}\right)$ and three mixing parameters (quiet bath, stirring at 320 RPM and sonication 1 to 10) were chosen to deposit aluminium on $25 \mathrm{~mm}$ diameter disks. The electrochemical set-up used is the one depicted in figure $2 \mathrm{~b}$. Table 5 summarizes the tested combinations. The sample at $20^{\circ} \mathrm{C}$ in in quiet condition was no studied since it required a very negative potential (close to $-4 \mathrm{~V}$ ) well below the $\mathrm{IL}$ potential window.

Deposition at high temperature combined with strong sonication duty cycle (30\%, 1 to 1$)$ resulted not suitable since the heating side effects of sonication, promoted the rapid degradation of the IL w orsening the quality of the obtained deposits. 
Table 5. Summary of the samples obtained by means of combined experimental conditions and, under brackets, their re lative process yield.

\begin{tabular}{c|ccc}
\hline Yield \% & $20^{\circ} \mathrm{C}$ & $40^{\circ} \mathrm{C}$ & $60^{\circ} \mathrm{C}$ \\
\hline Quiet Deposits & - & A $(45 \%)$ & B $(69 \%)$ \\
Stirring 320 RPM & C (82\%) & D $(100 \%)$ & E \\
& & & $(100 \%)$ \\
Sonication 1 to 10 & E (100\%) & F (100\%) & $\begin{array}{c}\text { G } \\
(100 \%)\end{array}$ \\
\hline
\end{tabular}

Roughness and morphological investigation on the deposit obtained using mechanical stirring and sonication are depicted in Figure 9 and Figure 10, respectively.

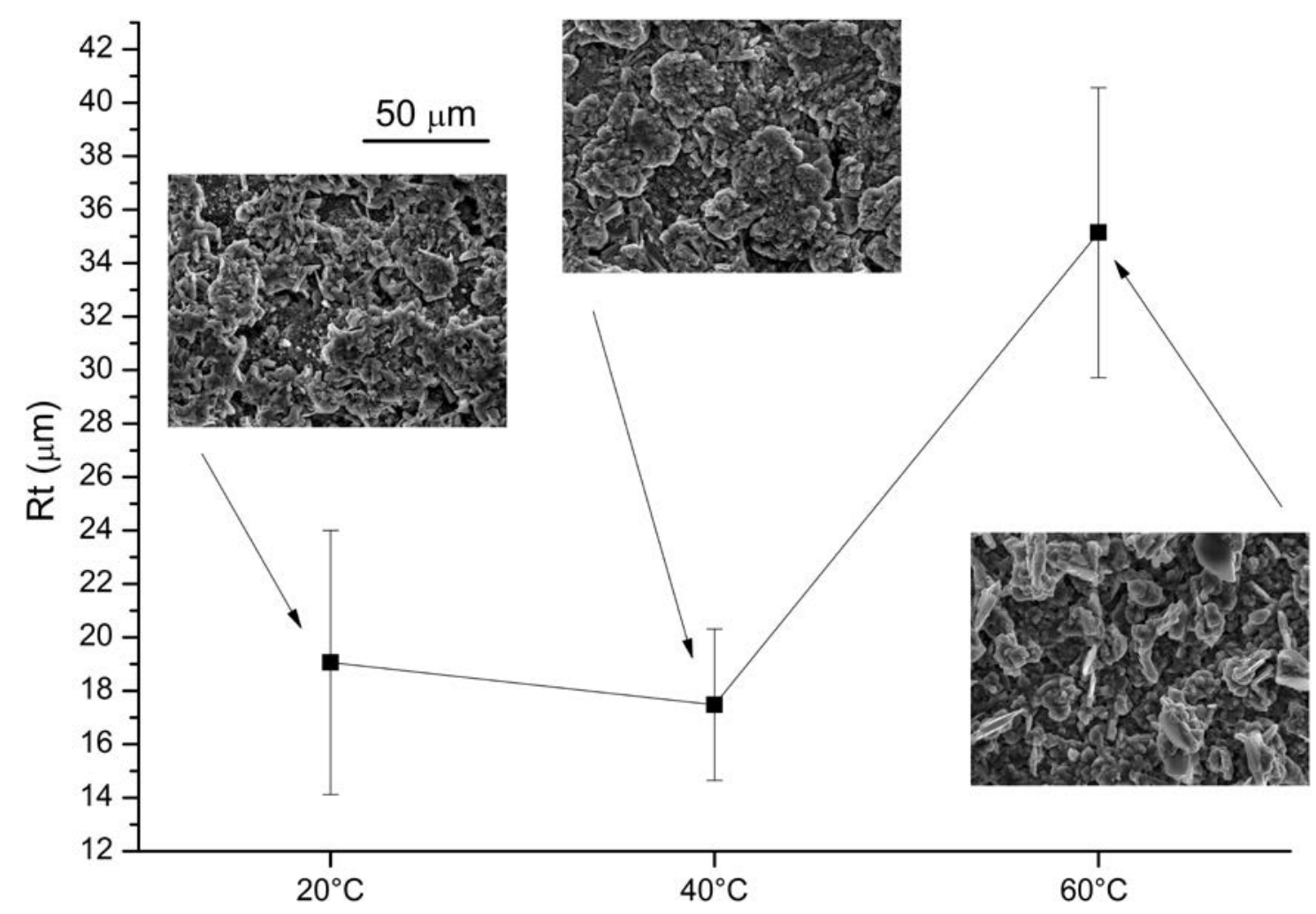

Figure 9. Roughness parameter and SEM images of the surface relative to the samples obtained by mechanical stirring (320 RPM) at different te mperatures. Scale bar $50 \mu \mathrm{m}$. 


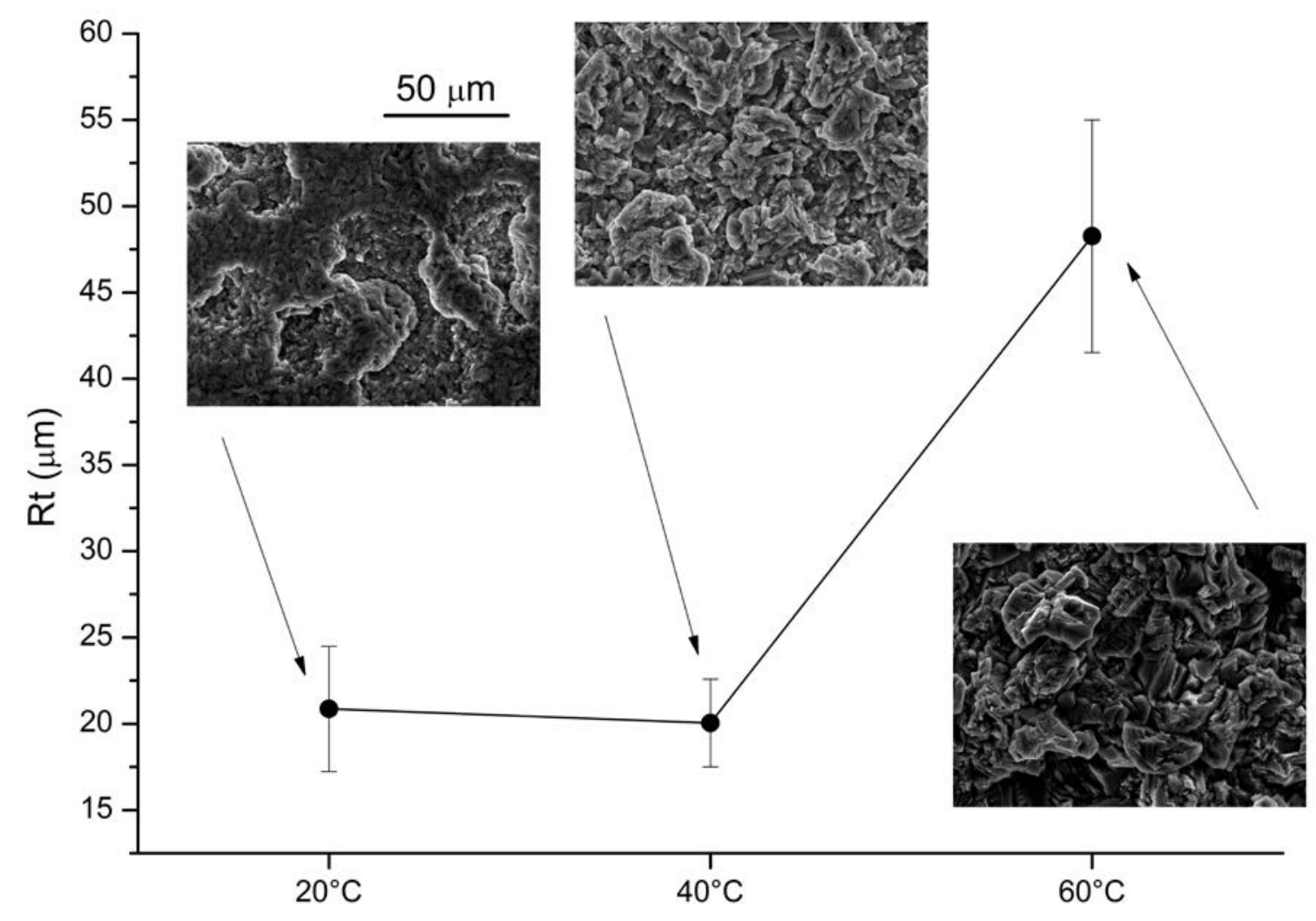

Figure 10. Roughness parameter and SEM images of the surface relative to the samples obtained via sonication ( 1 to 10 cycle) at diffe rent te mperatures. Scale bar $50 \mu \mathrm{m}$.

Table 5 also displays the deposition yields obtained for combined parameters. As expected, the yield increases as function of temperature (samples A and B). Mechanical stirring also promote the yield increase even if the $100 \%$ yield could be reached only for temperature higher than $40^{\circ} \mathrm{C}$ (samples C, D and E). Sonication grants $100 \%$ yield at every investigate temperature.

\subsubsection{Structural investigation}

Figure 11 shows the XRD patterns of the obtained samples compared with the simulated pow der Al pattern as defined in section 2.6. The texture coefficient obtained as described in section 2.6 are depicted in figure 12a. These data clearly show as the experimental conditions affect the texture of the deposits. Samples obtained by using mechanical stirring (samples C, D and E) present strong orientation of the crystal along (111) and (311) planes as function of the temperature increase. On the contrary, the texturing of plane (200) decreases with increasing temperature. On the other side, samples obtained by means of sonication (samples F, G and H) show the same temperature trend; the (111) and (200) planes are favored by temperature. It is worth to notice that, increasing the temperature up to $40^{\circ} \mathrm{C}$, the (311) plane is favored over (220) plane. At the same time sample obtained in quiet conditions (sample A and B) show an increasing texture coefficient for (111) and (311) planes as function of temperature increase, while (200) and (220) planes seems to be almost unaffected by temperature. 


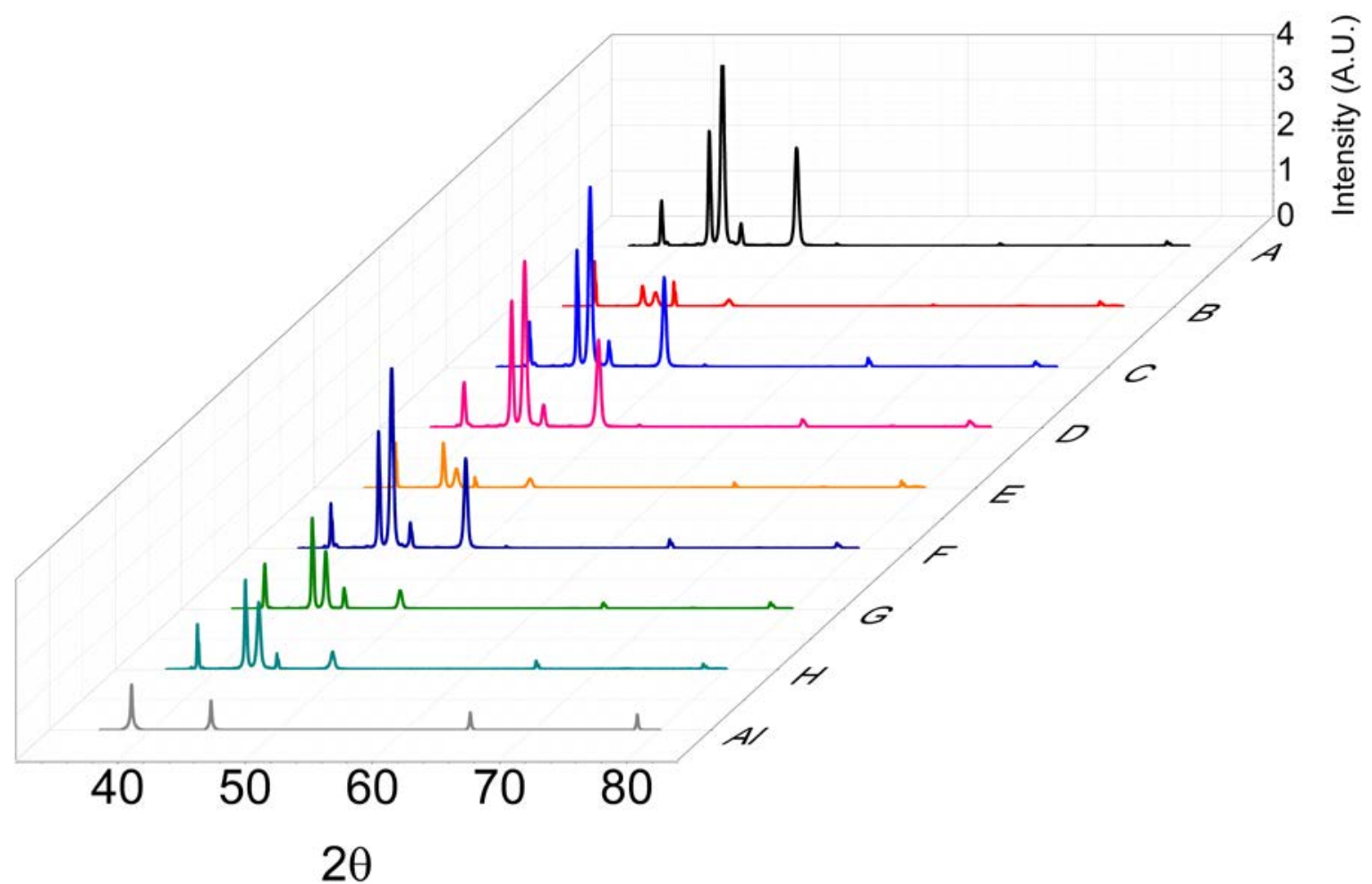

Figure 11 XRD patterns of the samples in Table 5 compared with the simulated powder alluminium pattern $(\mathrm{Al})$.

Figure $12 \mathrm{~b}$ reports the Gaussian widths of the XRD peaks. These values are related to the average strain of the crystallites. In the case on which the Gaussian width resulted undefined by the fitting process, the corresponding point is not depicted in figure $12 \mathrm{~b}$. It is worth to notice that for each plane the maximum of the Gaussian width, hence the minimum lattice strain was achieved in the deposits obtained at $40 \mathrm{C}^{\circ}$. In Figure $12 \mathrm{c}$ are reported the trends of the Lorentzian width, which is related to the average crystal size. The samples present different trends that are worth to be discussed in detail.

Temperature increase results in a strong decrease of the IL viscosity improving, in such a way, the mobility of the electroactive species [18]. As demonstrated by morphology investigation, transport phenomena affect both the size and morphology of the crystals. In fact, texture coefficient associated to the (111) and (311) planes results enhanced by the increased mobility in the electrolyte, that favors the grow th of these planes over the (200) plane.

The average strain of the crystallites is minimized at $40^{\circ} \mathrm{C}$ in both, stirring and sonication sets. It is worth to notice that the crystallites' average size shows trends much more complex than texture; in general, improving of mixing conditions do not affect the crystallite size, while the temperature does. Moreover, it can be observed inverse trends for sonication respect to stirring as function of the temperature increase. 
a

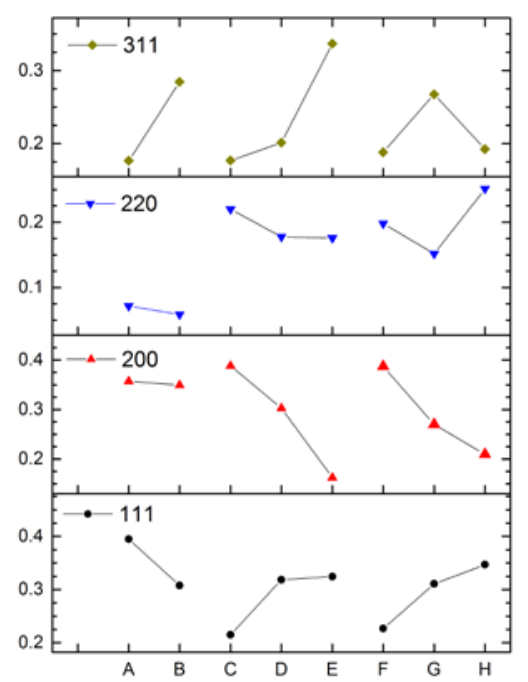

b

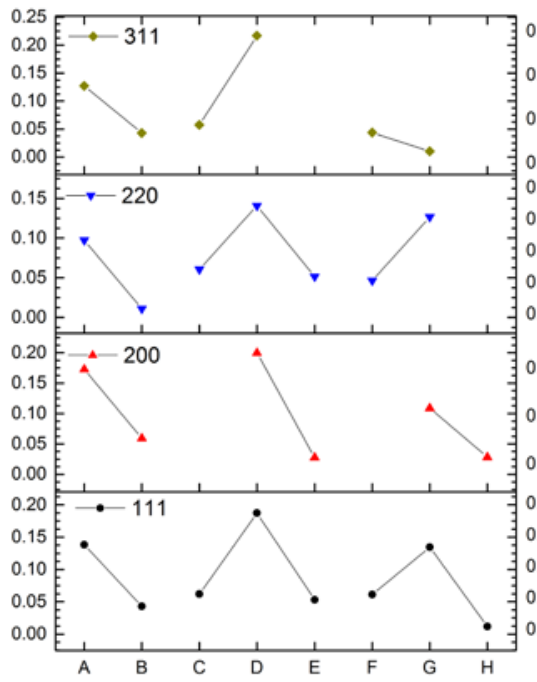

c

$\mathrm{wL}$

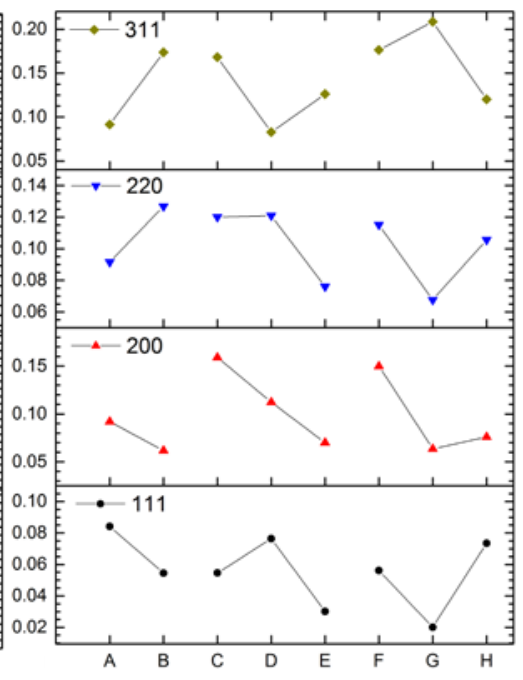

Figure 12. Trends of the best fits of the assigned peaks over the 3 different sets of results, a) the texture coefficient b) the Gaussian width (proportional to the average strain) and c) the Lorentzian width (proportional to the average size of the crystallites), some Gaussian width are not defined, thus not depicted in $b$ )

\section{Conclusions}

We have successfully prepared Al films on brass substrates by electrodeposition from $[\mathrm{Bmim}] \mathrm{Cl} / \mathrm{AlCl}_{3}$ 40:60 ionic liquid. The deposits were obtained varying temperature and mixing conditions. The surface morphology, the crystal orientation as well as the process yield results affected by these parameters. In particular, higher temperature and stronger mixing condition promote the deposition of smoother and thicker aluminium deposits. However, in order to move towards the industrialization of the process and therefore to increase the durability of the IL temperature above $60^{\circ} \mathrm{C}$ should be avoided. In order to speed up the electrodeposition process mechanical stirring or mild sonication can be successfully adopted.

Acknowledgments: The research leading to these results has received funding from the European Union Seventh Framework Programme (FP7/2007-2013) under grant agreement nº68698 .

Author Contributions: S.C. conceived and designed the experiments; E.B. and S.M. obtained the deposits and carried out their characterization; A.G. performed the XRD characterization and analyzed the data. All the authors contribute to write the paper.

Conflicts of Interest: The authors decla re no conflict of interest.

\section{Abbreviations}

The following abbreviations are used in this manuscript:

IL: Ionic Liquid

MDPI: Multidisciplinary Digital Publishing Institute

DOAJ: Directory of open a ccess journals

TLA: Three letter acronym

LD: linear dichroism 


\section{References}

1. Kai Grjotheim and Halvor Kvande, Introduction to aluminium electrolysis: understanding the Hall-Heroult process. Dusseldorf: Aluminium-Verlag, 1993.

2. S. Takahashi, N. Koura, S. Kohara, M.-L. Saboungi, and L. a. Curtiss, “Technological and scientific issues of room-temperature molten salts," Plasmas Ions, vol. 2, no. 3-4, pp. 91-105, 1999.

3. A. P. Abbott, R. C. Harris, Y.-T. Hsieh, K. S. Ryder, and I.-W. Sun, “Aluminium electrodeposition under ambient conditions.," Phys. Chem. Chem. Phys., vol. 16, no. 28, pp. 14675-81, 2014.

4. Y. Fang, K. Yoshii, X. Jiang, X. G. Sun, T. Tsuda, N. Mehio, and S. Dai, "An AlCl3 based ionic liquid with a neutral substituted pyridine ligand for electrochemical deposition of aluminum," Electrochim. Acta, vol. 160, pp. 82-88, 2015.

5. G. Pulletikurthi, B. Bödecker, A. Borodin, B. Weidenfeller, and F. Endres, “Electrodeposition of Al from a 1-butylpyrrolidine-AlCl 3 ionic liquid," Prog. Nat. Sci. Mater. Int., vol. 25, no. 6, pp. 603-611, 2015.

6. C. J. Su, Y. T. Hsieh, C. C. Chen, and I. W. Sun, "Electrodeposition of aluminum wires from the Lew is acidic $\mathrm{AlCl}$ 3/trimethylamine hydrochloride ionic liquid without using a template," Electrochem. commun., vol. 34, no. 7205, pp. 170-173,2013.

7. A. Endo, M. Miyake, and T. Hirato, "Electrodeposition of Aluminum from 1,3-Dimethyl-2-Imidazolidinone/AlCl3 baths," Electrochim. Acta, vol. 137, pp. 470-475, 2014.

8. Q. Wang, B. Chen, Q. Zhang, X. Lu, and S. Zhang, "Aluminum Deposition from Lewis Acidic 1-Butyl-3-Methylimidazolium Chloroaluminate Ionic Liquid ([Bmim] Cl/AlCl3) Modified with Methyl Nicotinate," ChemElectroChem, vol. 2, no. 11, pp. 1794-1798, 2015.

9. Q. Wang, Q. Zhang, B. Chen, X. Lu, and S. Zhang, “Electrodeposition of Bright Al Coatings from 1-Butyl-3-Methylimidazolium Chloroaluminate Ionic Liquids with Specific Additives," J. Electrochem. Soc., vol. 162, no. 8, pp. D320-D324, 2015.

10. J.-K. Chang, S.-Y. Chen, W.-T. Tsai, M.-J. Deng, and I.-W. Sun, “Electrodeposition of aluminum on magnesium alloy in aluminum chloride (AlCl3)-1-ethyl-3-methylimidazolium chloride (EMIC) ionic liquid and its corrosion behavior," Electrochem. commun., vol. 9, no. 7, pp. 16021606, Jul. 2007.

11. U. Bardi, S. Caporali, M. Craig, A. Giorgetti, I. Perissi, and J. R. Nicholls, “Electrodeposition of aluminium film on P90 Li-Al alloy as protective coating against corrosion," Surf. Coatings Technol., vol. 203, no. 10-11,pp. 1373-1378, 2009.

12. G. Yue, S. Zhang, Y. Zhu, X. Lu, S. Li, and Z. Li, "A promising method for electrodeposition of aluminium on stainless steel in ionic liquid," AIChE J., vol. 55, no. 3, pp. 783-796, Mar. 2009.

13. D. Pradhan and R. G. Reddy, "Dendrite-Free Aluminum Electrodeposition from AlCl3-1-Ethyl-3-Methyl-Imidazolium Chloride Ionic Liquid Electrolytes," Metall. Mater. Trans. B, vol. 43, no. 3, pp. 519-531, Jun. 2012.

14. R. K. Choudhary, V. Kain, and R. C. Hubli, "Stirring effects on aluminium coatings electrodeposited in ionic liquids," Surf. Eng., vol.30, no. 8, 2014.

(C) 2016 by the authors; licensee MDPI, Basel, Switzerland. This article is an open access article distributed under the terms and conditions of the Creative Commons by Attribution (CC-BY) license (http://creativecommons.org/licenses/by/4.0/). 